\title{
Simulation of an Excavator Hydraulic System Using Nonlinear Mathematical Models
}

\author{
Paolo Casoli* - Nicola Pompini - Luca Riccò \\ University of Parma Italy, Industrial Engineering Department, Italy
}

This paper describes a mathematical modelling methodology developed for the rapid simulation of an excavator hydraulic system. The modelling approach presented enables a reduction of the control system development time for a complete excavator, while providing accurate system dynamics. A tool for defining an appropriate control strategy is a key point for satisfying the need for systems with better energyefficiency. Moreover, the model will be a significant support in investigating energy recovery solutions and evaluating the suitability of hybrid solutions (mechanical/hydraulic/electric). The hydraulic model, composed of the pump's grey box model and the valve block white box model, has been validated on the basis of a set of experimental data collected on a test bench. The results of this study are presented in this paper. Keywords: hydraulic excavator, hydraulic system nonlinear modelling, variable displacement pump, load sensing, flow-sharing valve

Highlights
- The model of the hydraulic circuit could be used for control-oriented applications.
- $\quad$ The mathematical model is based on grey and white box models.
- Experimental validation of the pump model in both steady and dynamic conditions.

\section{INTRODUCTION}

There is an increasing demand in the field of construction equipment to simultaneously develop both a construction equipment system and a control strategy, especially when a short commissioning period is desired. Moreover, the manufacturer's engineering teams must satisfy the needs of operators in different geographical locations. Therefore, there is a need for a powerful software development tool, able to reproduce the behaviour of complex mechanical systems, such as large manipulators, mobile cranes and excavators, in transient conditions and with low calculation times, with the ultimate aim of realizing a "control-oriented" model able to perform real time simulations in a hardware in the loop (HiL) or software in the loop (SiL) environment. This approach can lead to great time savings, as it allows testing and debugging the control unit simultaneously with the development of the actual physical system to be controlled. In contrast, the development of a reliable multi-system model can be a valuable instrument in performing full system optimization, given the ability to simulate the interaction between various components (hydraulics, engine, and kinematics) under actual operating conditions. The ultimate aim of this research is to realize a customized control strategy, able to guarantee performance improvements (e.g. fuel consumption reduction) for the specific application. The complexity in modelling these systems is attributed to the inherently nonlinear hydraulic drive used to achieve precise motion and power control.

The hydraulic systems are characterized by a superior power density in comparison with electrical or mechanical systems, but hydraulic systems are less efficient due to the energy conversions involved. In order to reduce the energy losses, new system layouts are proposed [1] to [3], but typically the systems are designed for satisfying the load requirements controlling the fluid flow generated by the pumps. Variable displacement pumps are essential for controlling the flow; in axial piston pumps, the displacement can be varied by tilting the swash plate, which can be achieved fast enough to meet the dynamic demands due to multiple loads. The swash plate angular position is controlled by means of an actuator working in feedback with the load; these types of pumps are known as load-sensing pumps. The load signals from the actuators are transferred to the pump regulators through the load-sensing line. A load-sensing, flow-sharing valve block was used for the application considered; flow sharing is a useful feature when the global flow rate required by the various elements exceeds the pump's maximum flow rate, especially in excavators where several simultaneous motions are required.

A literature review shows that pump models could be conceived in a number of ways, either for analysing specific aspects in greater detail [4] to [6], or, 
on the basis of linear transfer functions, reproducing the pump's dynamic behaviour [7]. The first approach was clearly discarded, as the aim was to create a model suitable for reproducing pump behaviour, not a tool for pump design, while the second approach lacks the flexibility required to examine pumps in different working conditions, as the transfer functions would have to be modified each time. In this research, a grey box modelling approach has been followed, which represents a satisfactory compromise between the very short run time and the accuracy of results [8]. The following sections describe the modelling of the pump, the flow-sharing valve and the excavator kinematics; the validated results of the pump and valve models are also presented.

\section{PHYSICAL MODELING}

\subsection{Pump and Compensators Model}

The pump model described in this paper is that of a variable displacement axial piston pump. The pump is controlled by using two compensators: the pressure compensator (PC), which acts as a relief valve, limiting the maximum pressure of the system, and the flow compensator (FC), which modulates the outlet flow in order to obtain a specific pressure difference between the pump outlet and the loadsensing line. The pump model presented in this paper is an improvement on the grey box model developed by the authors and reported in [8]. The grey box model includes a white box model of the flow and pressure compensators, and a black box model of the pump flow characteristics. Significant improvements on the pump black box model are presented in this paper; specifically, a more detailed stationary correlation between the pump swash plate actuator pressure and pump delivery pressure, swash plate position and pump shaft rotary speed is obtained. Moreover, the calibration of the viscous friction coefficient (Eq. (3)), which greatly affects the swash plate dynamic, was carried out on the basis of experimental dynamic tests. The mathematical models were developed using the AMESim $^{\circledR}$ simulation software.

\subsubsection{Pressure and Flow Compensator Model}

The compensators were previously modelled and verified in detail [8]. The pressure and flow compensator models are based on a fluid-dynamic model (FDM) and a mechanical-geometrical model (MGM). The FDM calculates the pressures inside the chambers and the flow rate between adjacent chambers, while the MGM calculates the forces acting on the spool and determines its position and the corresponding flow areas. The FDM and the MGM are both based on a lumped parameter framework. The pressure inside each control volume is assumed to be spatially uniform and time dependent; a pressure-rise rate in Eq. (1) is obtained from the continuity equation and the state equation of the fluid:

$$
\frac{d p_{i}}{d t}=\frac{\beta}{\rho_{i}} \frac{1}{V_{i}(x)}\left(\sum \dot{m}-\rho_{i} \frac{d V_{i}(x)}{d t}\right),
$$

where the volume of the chamber is derived from the instantaneous position of the spool $(x)$. The model assumes a constant value of fluid temperature. The fluid density is evaluated as a function of pressure as described in [9] and [10]. The summation term represents the net mass flow rate entering or leaving the volume. This is obtained by considering the contribution of all orifices connected with the volume considered. The mass exchange occurring through the orifices is calculated using Bernoulli's generalized equation under quasi-steady conditions [8] and [9]. The forces acting on the spool are hydrostatic forces, the spring forces, friction forces, and hydrodynamic forces. The hydrodynamic forces have been neglected. The model employed is a slightly simplified version of an already verified one [8], in which redundant chambers and leakages (which have been proved to have a very low impact on the accuracy of simulation results) were removed in order to reduce the computation time. The corresponding increase in the volume of the remaining chambers also had a positive effect. Eq. (1) shows that hydraulic components have a considerably small time constant since mineral oils have a high bulk modulus $\beta(\sim 1700 \mathrm{MPa})$; therefore, even small flow rates induce high variations in the chamber pressure. The increase in chambers volume, therefore, leads to less stiff behaviours.

\subsubsection{Flow Characteristics Model of the Pump}

The basic idea of the model is to consider the pump as a simple flow generator whose output is a function of both the given rotary speed (usually a constant value set in the range of $750 \mathrm{r} / \mathrm{min}$ to $2300 \mathrm{r} / \mathrm{min}$ ) and the instantaneous displacement geometrically related to the swash plate angular position.

$$
\dot{V}_{t h}=V_{d}(\alpha) \cdot n \text {. }
$$

The flow characteristic of the pump, therefore, is closely correlated to the equilibrium of the swash plate expressed through Newton's second law. 


$$
J_{E Q} \ddot{\alpha}+c \dot{\alpha}=\sum_{n=1}^{N} T_{n}+T_{A C T} .
$$

The viscous friction coefficient was set on the basis of dynamic experimental tests, as reported in Section 3. While the control actuator torque was successfully evaluated by developing a white box model of the compensators, the determination of the barrel torque proved to be quite elaborate, requiring the identification of a great number of parameters (such as the determination of pressure in each pumping piston, damping effects, the length and diameter of the pistons masses, valve plate geometry, etc.). Therefore a black box model was preferred to determine the barrel torque, in order to provide a fast but still reliable model of the system. This was achieved by measuring the pressure in the pump swash plate actuator chamber (proportional to the control actuator torque) at given values of pump delivery pressure $\left(p_{D}\right)$, swash plate angular position, and at different rotary speeds.

At steady-state conditions, being $\dot{\alpha} \cong 0$, Eq. (3) guarantees the equivalence: $\sum_{n=1}^{N} T_{n}=T_{A C T}$. Thus, given the area of control actuator piston and the arm of the actuating force, a correlation between the pump actuator pressure and barrel torque exists (Eq. 4):

$$
\sum_{n=1}^{N} T_{n}=p_{A C T}\left(p_{D}, \alpha, n\right) \cdot A_{A C T} \cdot d_{A C T} .
$$

Through a surface fitting tool, a correlation was provided between the pressure in the pump actuator chamber and both the swash plate angular position and the pump outlet pressure, for a given set of pump shaft rotary speeds between $850 \mathrm{r} / \mathrm{min}$ to $2250 \mathrm{r} / \mathrm{min}$ (Fig. 1). The influence of the shaft rotary speed is the main improvement from the work presented in [8].

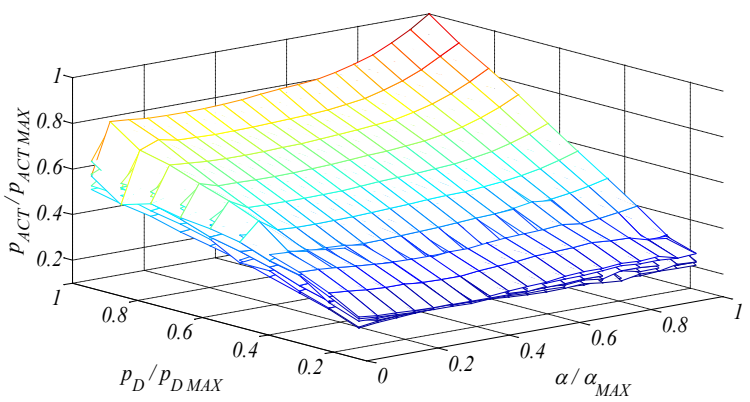

Fig. 1. Actuator pressure, $p_{A C T}=f\left(p_{D}, \alpha, n\right)$

A suitable experimental activity was carried out to improve the model's accuracy in calculating the swash plate actuator pressure when the pump shaft rotary speed varies. Fig. 2 shows a comparison between the experimental data and the simulation results. For confidential reasons, a more detailed explanation of the experimental setup cannot be provided here. It can, however, be observed that the new model actuator pressure presents a much better match with the experimental results if compared to the original model during pump speed variations.

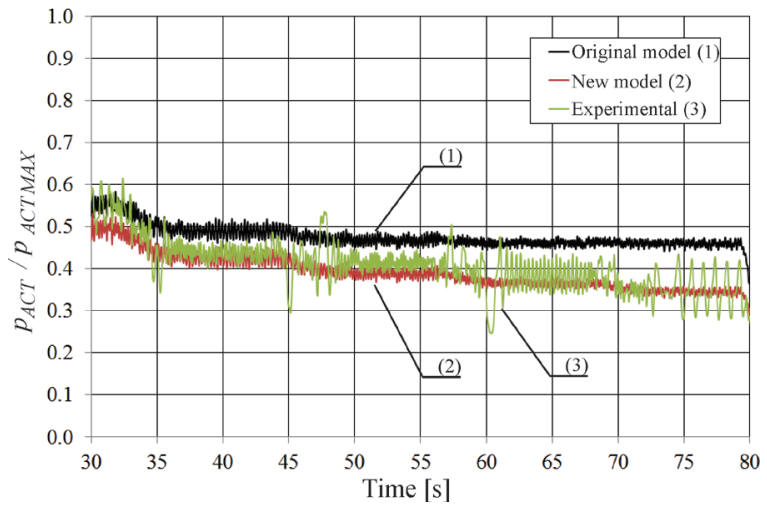

Fig. 2. Original and new pump model - actuator pressure comparison with experimental data

Hydraulic-mechanical and volumetric efficiencies were experimentally determined according to the ISO 4409:1986 standard [11]. Overall efficiency is reported in Fig. 3 at the maximum pump displacement values.

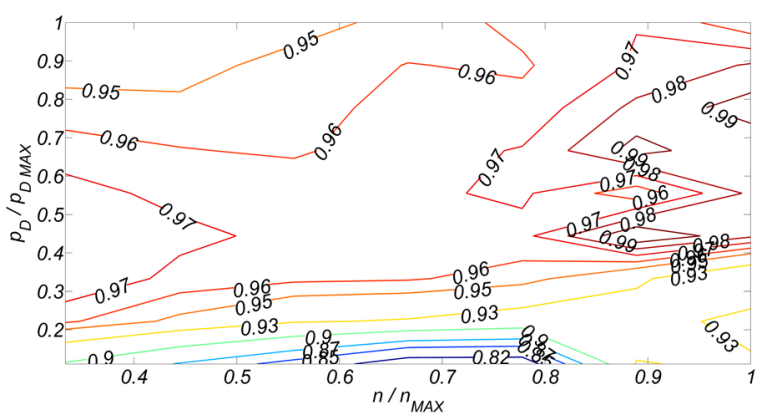

Fig. 3. Pump normalized overall efficiency, $\eta_{g} / \eta_{g M A X}$ at $\alpha / \alpha_{M A X}=1$

The real flow outlet is thereby calculated as:

$$
\dot{V}=\eta_{v}\left(p_{D}, \alpha, n\right) \cdot \dot{V}_{t h},
$$

while the torque required at the motor shaft is:

$$
T=\frac{\Delta p \cdot V_{d}(\alpha)}{2 \pi} \cdot \frac{1}{\eta_{h m}\left(p_{D}, \alpha, n\right)} .
$$

\subsection{Directional Valve Model}

The excavator under study is equipped with a loadsensing full flow-sharing valve block (Walvoil ${ }^{\circledR}$ DPX), 
which is very effective for this kind of application. During a digging cycle, at least three valve sections are generally used at the same time, which could lead to the pump working in flow saturation conditions, i.e. the pump maximum flow is less than the flow required by the system. The operator might lose the direct control of the moving parts if this situation occurs in machinery in which a standard load-sensing (LS) circuit is adopted. A flow-sharing valve prevents this happening by evenly decreasing the flow to all the moving parts, thus maintaining the controllability of movements at the expense of a reduced velocity. The valve block is composed of multiple sections, each of which defines the outlet flow toward a specific actuator, extrapolates the LS pressure, maintains a constant pressure drop across the main spool metering area and provides the flow-sharing operation condition if required. A simple mathematical model cannot recreate all these functioning conditions. Therefore, the valve mathematical model was developed as a simplified valve model able to recreate the actual working conditions of the valve. Figure 4 shows the ISO scheme of a valve section.

The valve white box model has already been developed and validated [12], with a comparison between simulation and experimental results obtained in laboratory tests. The model is based on the same equations used for the pump flow compensator (section 2.1.1). The hydrodynamic forces acting on the spools were neglected, because the model was not conceived for design purposes, but as a tool for reproducing valve dynamic behaviours guaranteeing short simulation times.

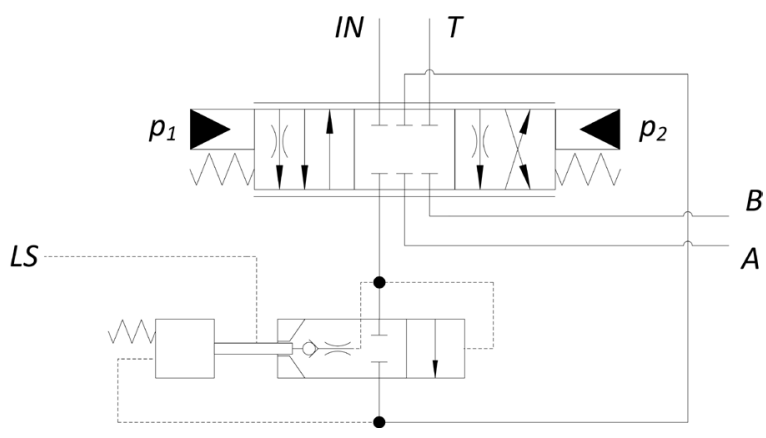

Fig. 4. Directional Flow Control Valve ISO scheme

\subsection{Kinematics and Actuators Model}

This section describes the modelling of the excavator's front tool kinematics, which was modelled to recreate the realistic forces acting on the hydraulic actuators during the movements. The kinematic model was coupled with the hydraulic model using the Planar Mechanics library of AMESim ${ }^{\circledR}$ [13]. The excavation tool is composed of a boom, arm and bucket that are moved by means of hydraulic actuators. The kinematics were implemented as a lumped parameter model [8], [14] and [15]. The model is not yet intended to simulate the forces acting on the bucket during its interaction with the soil [16]. The kinematics model calculates the dynamic loads on the hydraulic cylinders as well as the instantaneous positions and the velocities of piston actuators. The hydraulic actuator model includes pressure dynamic calculation, according to Eq. (1), in the volumes at each side of the piston. Eq. (2) defines the mass flow rate in the volumes, also taking into account the leakages between the chambers.

The friction forces acting on the cylinder piston are derived from viscous and Coulomb friction in agreement with other research [17]. Due to the model causality, the viscous friction is only considered in the hydraulic actuator model.

\section{EXPERIMENTAL SETUP}

\subsection{Experimental Setup and Tests on the Pump}

Fig. 5 depicts the test rig ISO scheme used to analyse the pump's dynamic behaviour and estimate the viscous friction parameter $c$ (Eq. (3)). Table 1 reports the instrumentation used for the tests. The test bench is also equipped with an off-line circuit for oil temperature control, consisting of a heat exchanger system that is electronically regulated to maintain a specified working temperature $\left(50^{\circ} \mathrm{C}\right)$. The pump was equipped with an angular sensor directly connected to the swash plate, where a torque limiter is typically mounted. A proportional flow control valve (A) was inserted on the pump outlet line to regulate the outgoing flow rate; a proportional relief valve (B) was inserted to maintain the system pressure at a desired set-point.

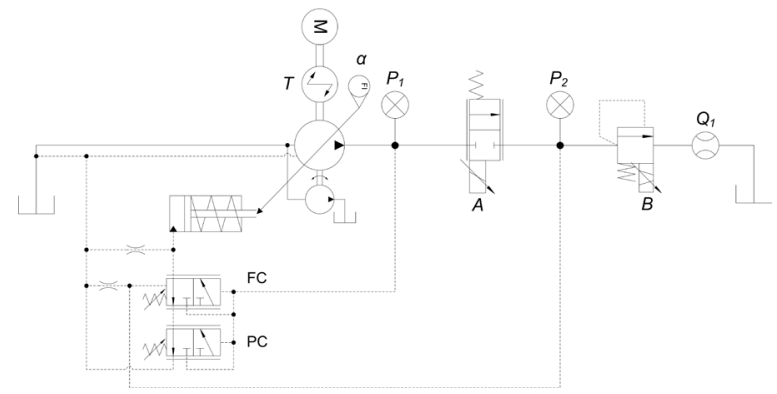

Fig. 5. Experimental setup for pump testing 
The phenomenon of interest, i.e. the pump swash plate variation derived from the pressure difference induced by the opening variations of the control valve (A) was estimated as lower than $50 \mathrm{~Hz}$, due to preliminary step response tests. According to the Nyquist-Shannon sampling theorem, a sample rate frequency of $200 \mathrm{~Hz}$ was chosen to avoid aliasing errors.

Table 1. Features of sensors and main elements of the experimental apparatus used in the present research

\begin{tabular}{lcc}
\hline Sensor & Type & Main features \\
\hline$M$ & Electric Motor & $\begin{array}{c}\mathrm{ABB}^{\circledR}, \text { 4-quadrant electric motor, } \\
75 \mathrm{~kW}\end{array}$ \\
\hline$P$ & Pump & $\begin{array}{c}\text { variable displacement axial piston } \\
\text { pump, } 84 \mathrm{~cm} / \mathrm{r}\end{array}$ \\
\hline$P_{1}$ to $P_{8}$ & Strain gage & $\begin{array}{c}\text { Trafag }{ }^{\circledR}, \text { Scale } 0 \text { to } 40 \mathrm{MPa}, \\
0.3 \% \text { FS accuracy }\end{array}$ \\
\hline$Q_{1}$ to $Q_{2}$ & Flow meter & $\begin{array}{c}\text { VSE }{ }^{\circledR} \text { VS1, Scale } 0.05 \text { to } 80 \mathrm{l} / \mathrm{min}, \\
0.3 \% \text { measured value accuracy }\end{array}$ \\
\hline T & Torque meter & HBM ${ }^{\circledR}$ T, Scale: 0 to $500 \mathrm{Nm}$, \\
\hline LVDT & Linear variable & 0.05 Accuracy Class \\
\hline
\end{tabular}

\subsubsection{Testing Conditions}

The tests were carried out with the LS pressure kept constant by using the proportional relief valve (B). A swash plate position $(\alpha)$ dynamic transient was induced by a step variation of the servo proportional flow control valve (A) area. A typical transient behaviour of the pump swash plate on a flow step demand is reported in Fig. 6, while Fig. 7 shows the correspondent dynamic variation of LS and delivery pressure.

\subsection{Experimental Test Setup: Valve Block and Pump}

A suitable experimental setup was provided to test the functioning of the valve block and pump system. The hydraulic circuit ISO scheme is represented in Fig. 11. The tests were carried out by using the valve block, composed of two valve sections, coupled with the variable displacement axial piston pump, with a connection between pump FC and valve LS line. The pump was equipped with an angular sensor directly connected with the swash plate, as previously explained.

Fig. 8 illustrates the cross-section of each valve section along with the pressure-mapping points; the two linear variable differential transformers (LVDT) are connected to the main spool and the pressure

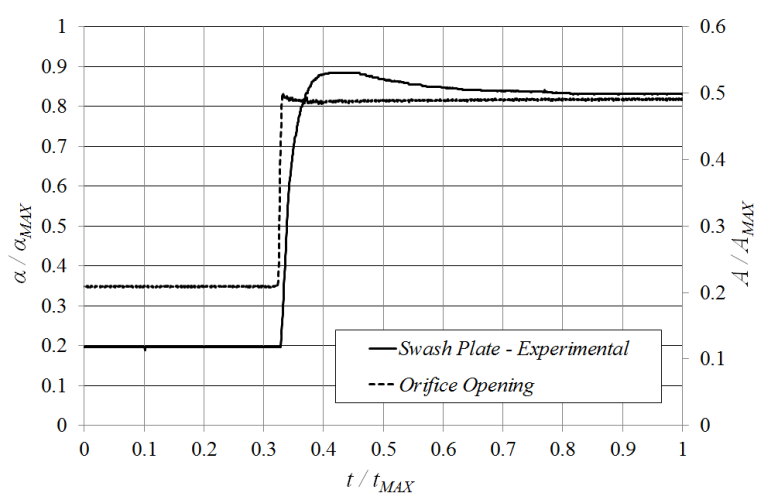

Fig. 6. Pump swash plate dynamic response to a step variation of the required flow rate

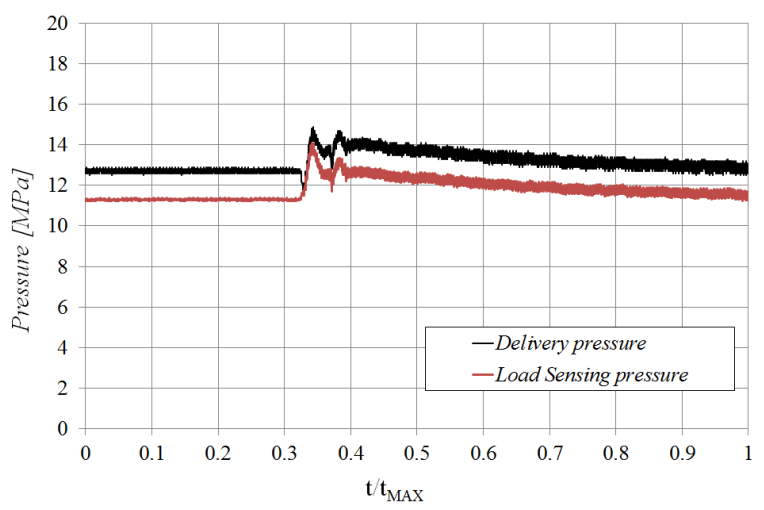

Fig. 7. Delivery pressure response to a step variation of the required flow rate

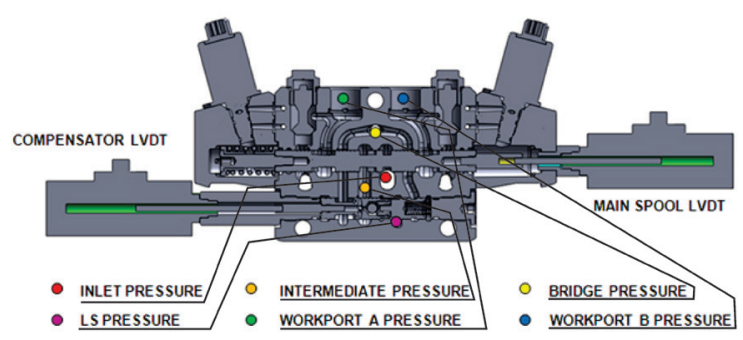

Fig. 8. Valve with installed LVDT and pressure mapping points

compensator spool. As shown in Fig. 11, two test bench lines were used to recreate the load on the two valves' outlet section. The lines are equipped with a flow meter and a proportional relief valve. A bleed valve was installed on the load-sensing line to maintain the line drained. The system was tested under standard working conditions, i.e. no flow saturation. The inputs of the experimental test were recorded and used as inputs for the simulation. The pump margin pressure was set at $2 \mathrm{MPa}$, i.e. pump delivery pressure was to be $2 \mathrm{MPa}$ above the load-sensing pressure. The pump shaft rotary was set at a constant value of 


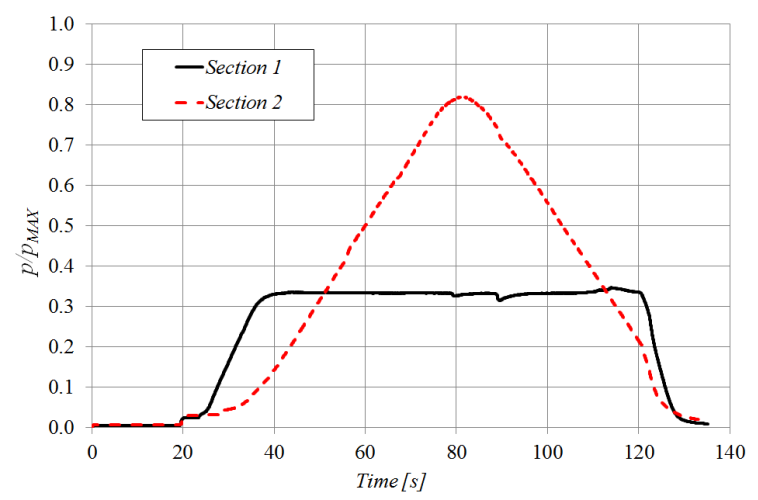

Fig. 9. Imposed loads to the valve sections

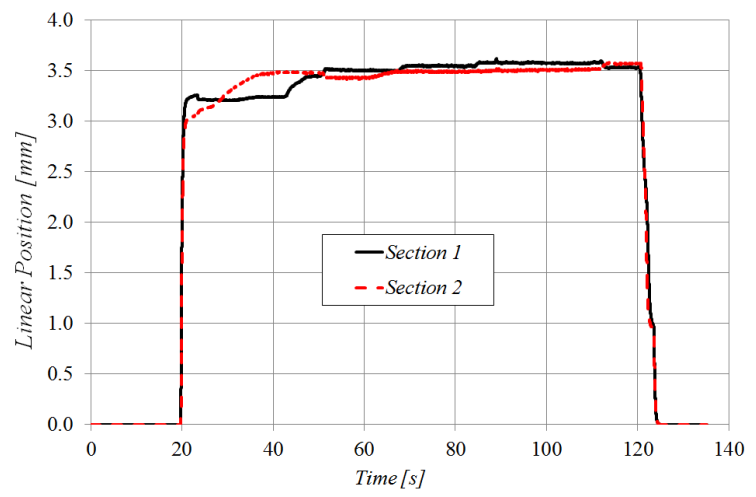

Fig. 10. Valve's main spools displacement

$1500 \mathrm{r} / \mathrm{min}$. Fig. 9 illustrates the loads imposed on the valve sections by means of the test bench proportional relief valves. Fig. 10 shows each section's main spool position, imposed on the valves and acquired through the LVDTs. The double pressure compensation cycle, whose valve users pressures and main spools opening are reported in Figs. 9 and 10 respectively, is very useful to verify the valve's compensators behaviour, as the role of the main section (i.e. the one which provides the load-sensing signal) was switched during the simulation; this also means that the intermediate pressure inside the compensated section (i.e. the one connected to the minor load) had to be modulated by the compensator in order to maintain the desired pressure drop across the metering area. This testing condition provides realistic boundary conditions, useful for testing the valve's behaviour.

\section{COMPARISON OF EXPERIMENTAL AND SIMULATION RESULTS}

\subsection{Pump}

The experimental boundary conditions (pump shaft rotary speed, LS pressure, servo proportional valve opening and FC pressure set point) were imposed as inputs to the pump mathematical model. Figs. 12 to 14 show the comparison between the experimental and numerical results regarding dynamic tests on the pump, performed at constant shaft rotary speed (equal to $1500 \mathrm{r} / \mathrm{min}$ in cases $a$ and $c$; and $2000 \mathrm{r} / \mathrm{min}$ in case $b$ ) and constant LS pressure (equal to $10.5 \mathrm{MPa}$ in cases $a$ and $b$; and $18.5 \mathrm{MPa}$ in case $c$ ).

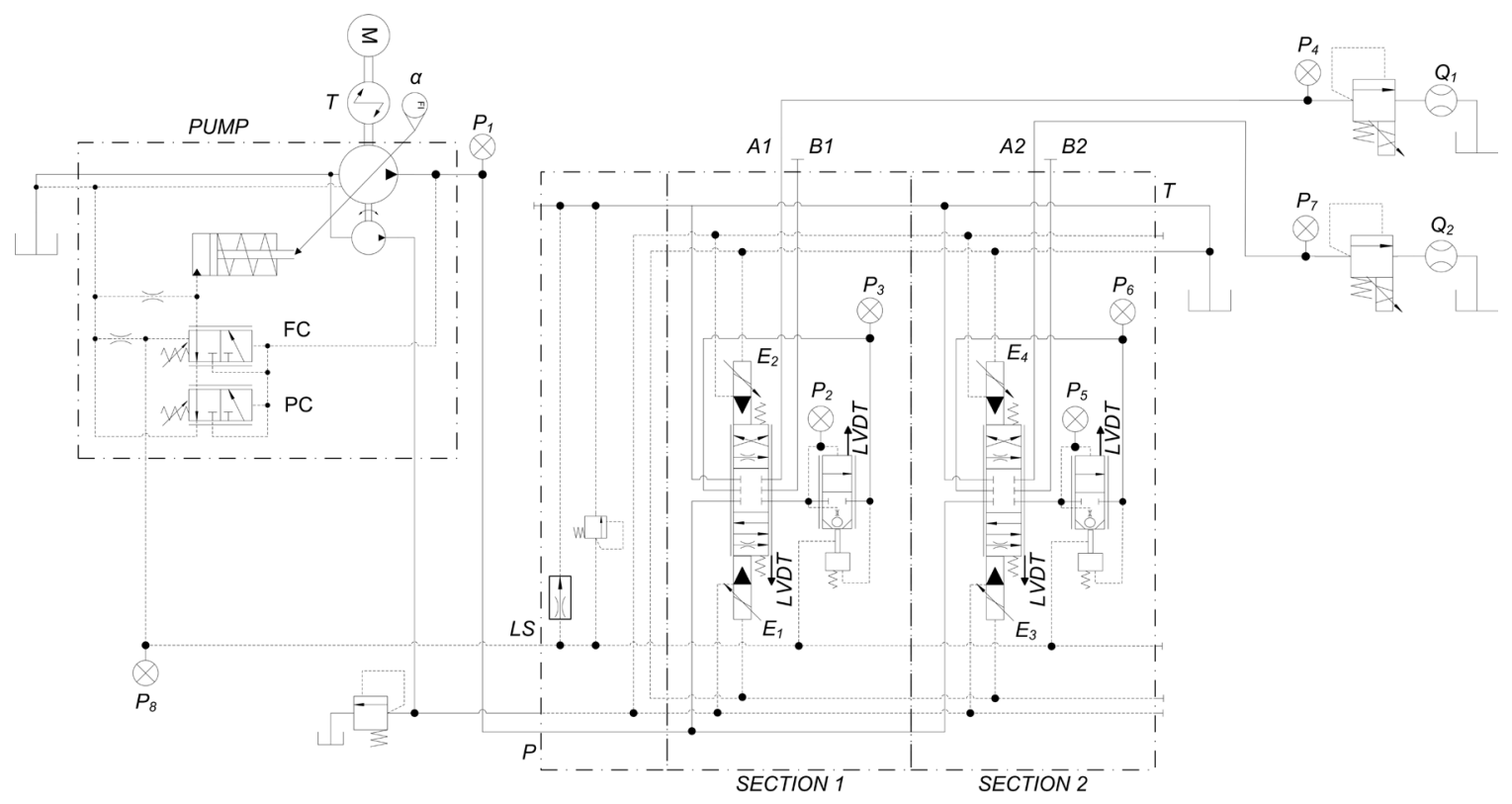

Fig. 11. Test setup for load-sensing, flow-sharing valve block 
A satisfying match between the experimental and simulated swash plate positions is noticeable, as the simulated curve presents both overshoot and time constant very close to that from acquisitions for each of the working conditions tested.

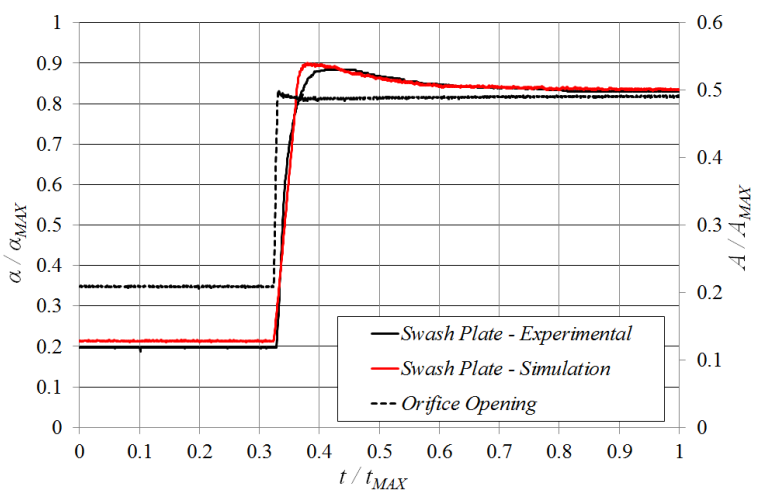

Fig. 12. Pump swash plate step response; case a

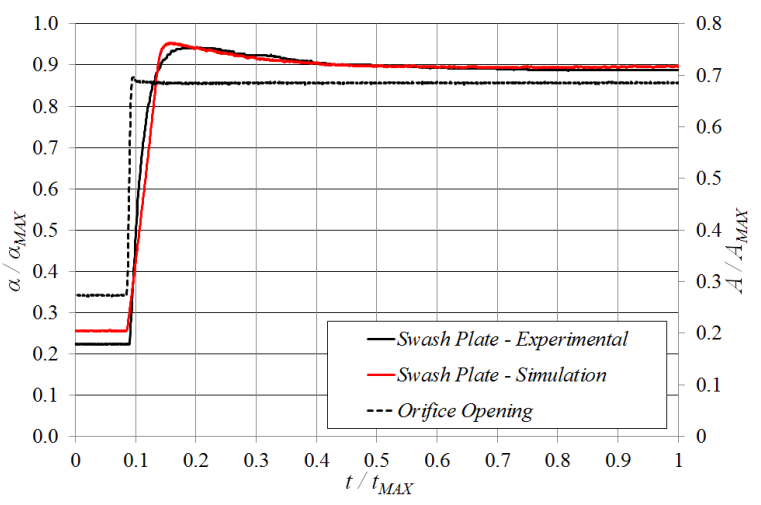

Fig. 13. Pump swash plate step response, case $b$

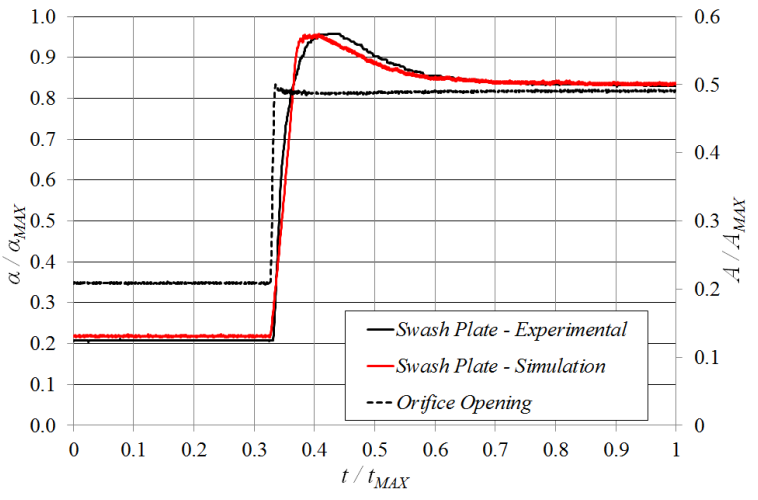

Fig. 14. Pump swash plate step response; case c

\subsection{Pump and Valve block}

The simulations were performed using the load pressures and the pump shaft rotary speed recorded during experimental tests as inputs. The valves opening were set equal to the experimental values acquired through the LVDTs installed.

Figs. 15 and 16 show the comparison between the experimental data and the simulation results for the intermediate chamber (see Fig. 8) of both valve sections. While the bridge chamber pressure is essentially equal to the effective load pressure as the pressure drop at the valve outlet is rather small due to large flow areas, the pressure in the intermediate chambers is equal to that of the section with the highest load (main section). That is to say, for the main section, the pressure drop across the compensator orifice is reduced as the compensator opens completely, while in the compensating section the flow is laminated in order to establish a pressure equal to that in the load-sensing line (i.e. the greatest one). The difference between the experimental values and the simulated one is less than $1 \%$. Figs. 17 and 18 report the experimental and simulated positions of the compensator in both sections. As anticipated, when a section is compensating, the compensator laminates the flow in order to re-establish the desired pressure drop across the metering area and thus maintain the desired flow rate.

The pressure in the load-sensing line is essentially equal to that of the main section intermediate chamber, while the pump outlet pressure, i.e. valve inlet pressure (Fig. 19), is regulated by the flow compensator in order to be $2 \mathrm{MPa}$ greater than the load-sensing pressure. The difference between experimental and simulated values is still less than $1 \%$.

The outlet flow rate for both sections is shown in Figs. 20 and 21, and the swash plate angular position in Fig. 22. A good match exists between experimental and simulated data, with a maximum error in the evaluation of the outlet flow rate in the order of $10 \%$ of the maximum value, which is also ascribable to measuring errors in the main spool position, as the pressure perfectly matches that acquired.

\section{EXCAVATOR MODEL AND SIMULATION}

The results presented in the previous section show that the pump and valve models are capable of reproducing actual system working conditions. Thus, the model was extended to include the kinematics of a real excavator [8] and [18], and its hydraulic circuit ISO scheme is reported in Fig. 25. In order to present the capability of the complete model, it was subjected to a duty cycle described in Fig. 23, where the three valve spools were operated to simulate real operator actions during a typical digging cycle (without bucket-soil interaction), with the simultaneous opening of two or 


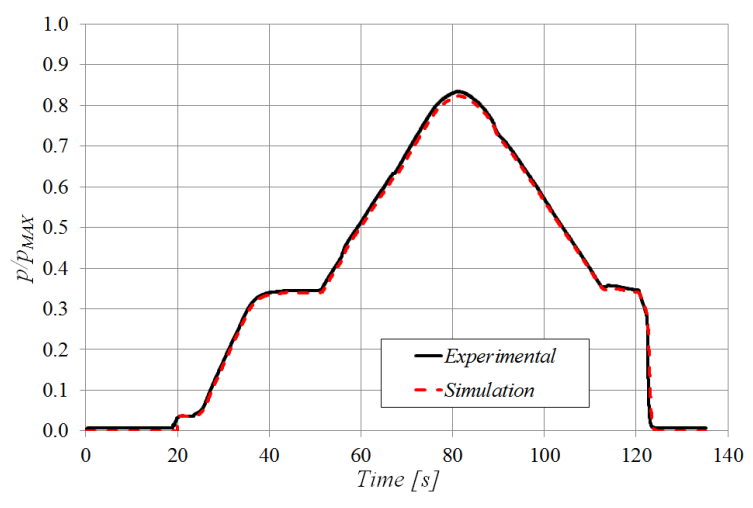

Fig. 15. Valve section 1 intermediate pressure

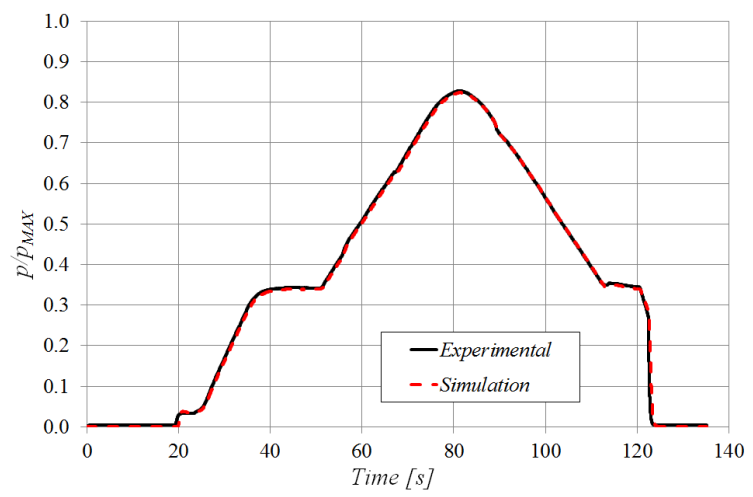

Fig. 16. Valve section 2 intermediate pressure

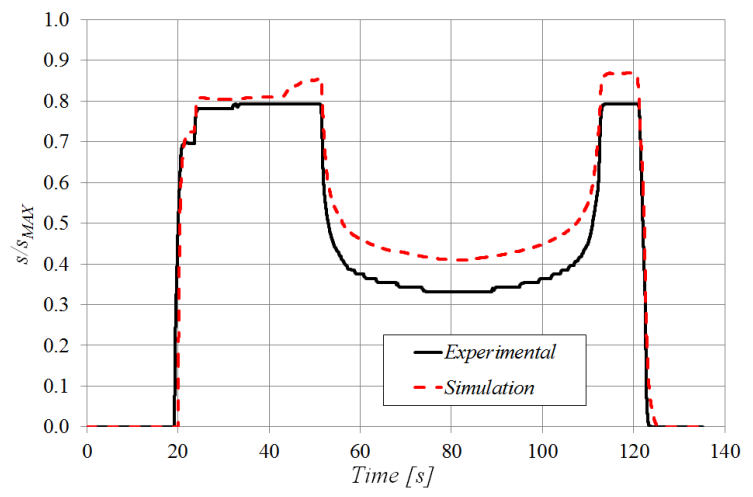

Fig. 17. Valve section 1 compensator displacement

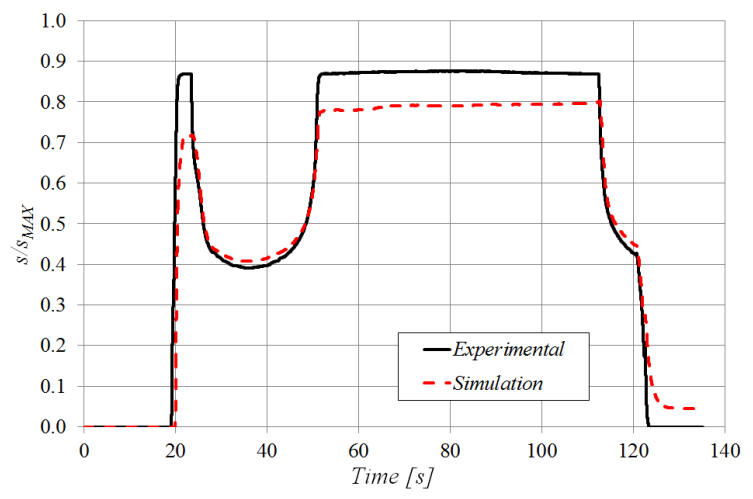

Fig. 18. Valve section 2 compensator displacement

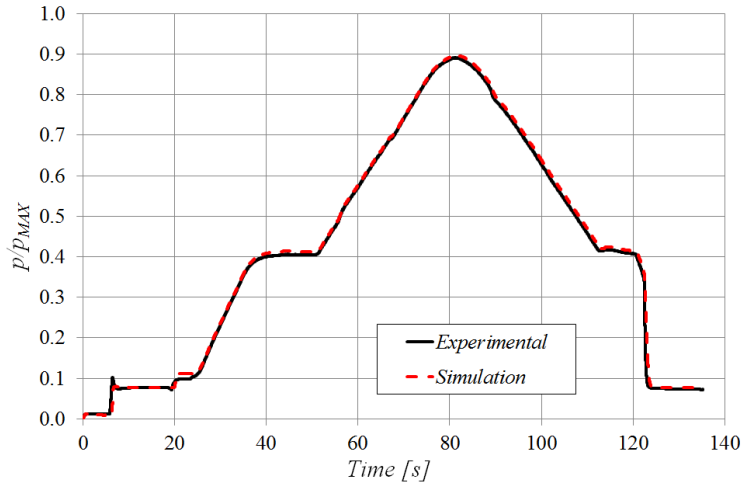

Fig. 19. Valve inlet pressure

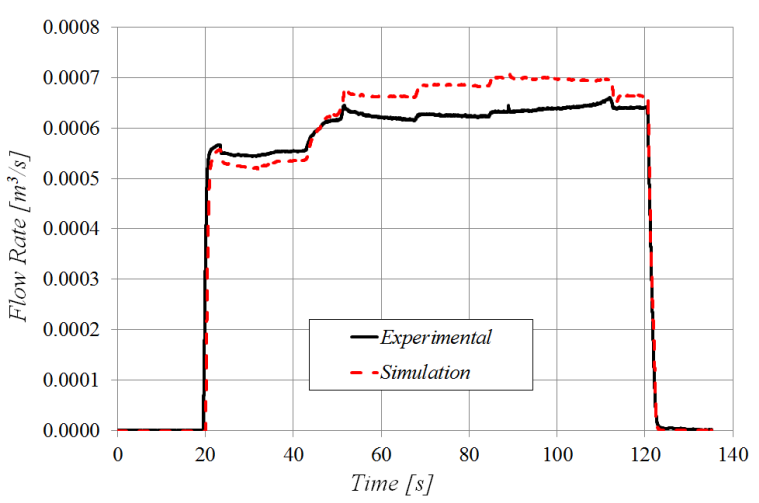

Fig. 20. Valve section 1 outlet flow rate

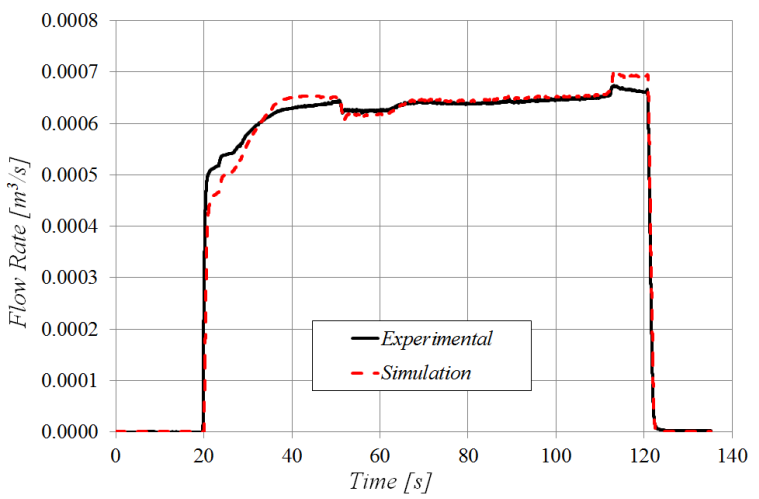

Fig. 21. Valve section 2 outlet flow rate

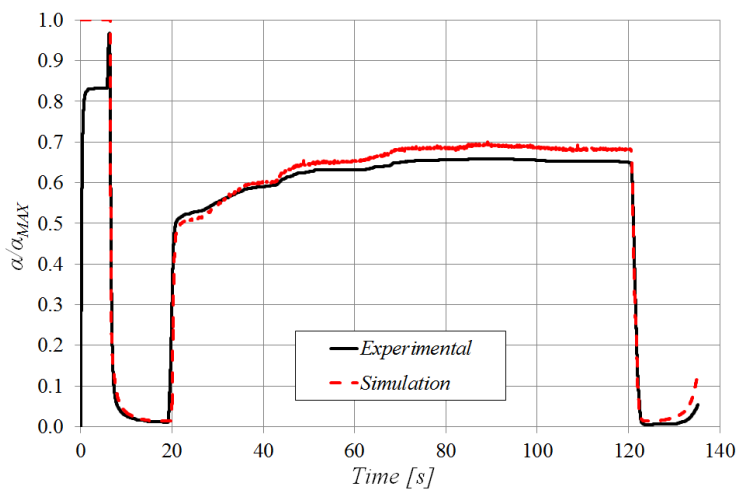

Fig. 22. Pump swash plate position 
three valves. Because the external forces acting on the bucket were not considered, the load on the actuators is only due to inertial effects (as a consequence of boom, arm and bucket movements) and gravitational forces. Fig. 24 shows the instantaneous velocity of the excavation tool hydraulic actuators. Figs. 26 to 28 illustrate the pressure in boom, arm and bucket actuators, and the valve bridge chambers.

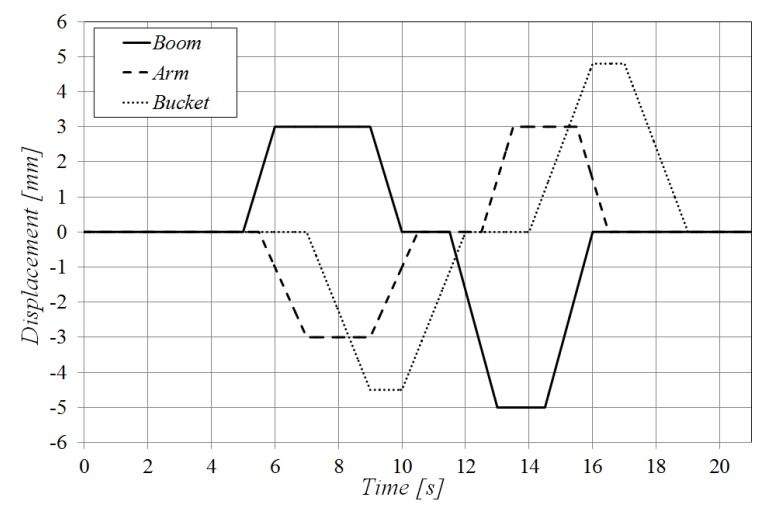

Fig. 23. Excavator duty cycle - valve main spools position

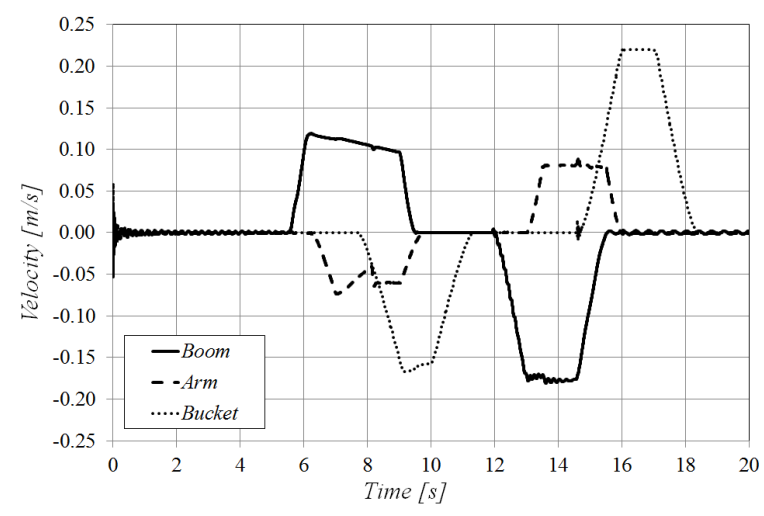

Fig. 24. Actuators velocity

Fig. 26 shows the oscillations due to the implements' inertial load, e.g. between $13 \mathrm{~s}$ and $15 \mathrm{~s}$ the boom velocity oscillates as a consequence of the simultaneous arm movements. Fig. 29 reports the pressure in the LS line and at the pump delivery line, the LS pressure line can be deduced by analysing Figs. 26 to 28 , as a matter of the fact of where the LS line is the higher pressure request from the concurrent users. The flow rates through various valves can be seen in Fig. 30; as expected, the flow rate is not influenced by the effective load condition and is only a function of the valve opening, Fig. 23, as well know this is a feature of the LS systems. Fig. 31 represents the swash plate instantaneous position, held to guarantee the specific pump margin at the desired flow rate.

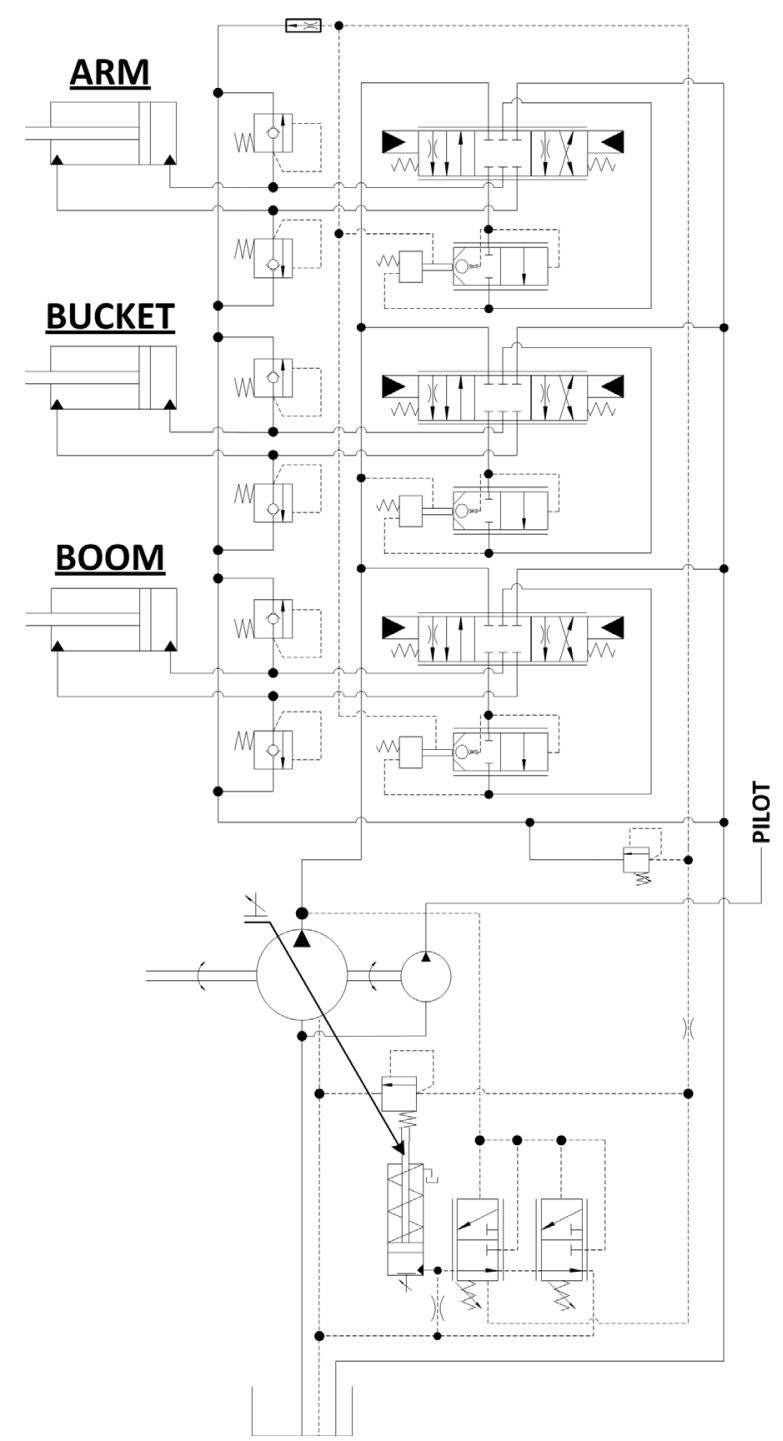

Fig. 25. Excavator's hydraulic system ISO scheme

Figs. 29 and 30 show the capability of the pump model to follow the request of the valve-opening law (flow rate demand) and to provide the correct delivery pressure in order to satisfy the load demand.

\section{CONCLUSIONS}

This paper presents a nonlinear mathematical model of an excavator hydraulic circuit, developed in the AMESim ${ }^{\circledR}$ modelling environment, able to replicate system actual operating conditions. The model is composed of hydraulic sub-models comprising a loadsensing variable displacement axial piston pump, a flow-sharing multi-section valve model and a 2D kinematic model to simulate the excavator's front excavation tool elements. The modelling approach 


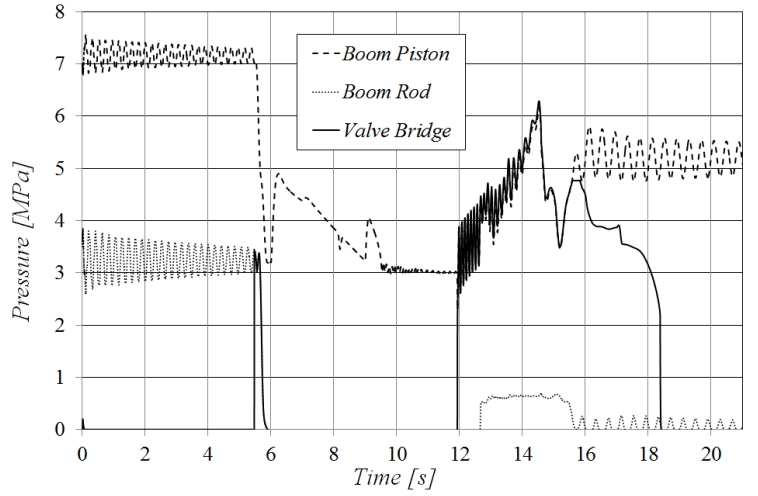

Fig. 26. Boom section pressures

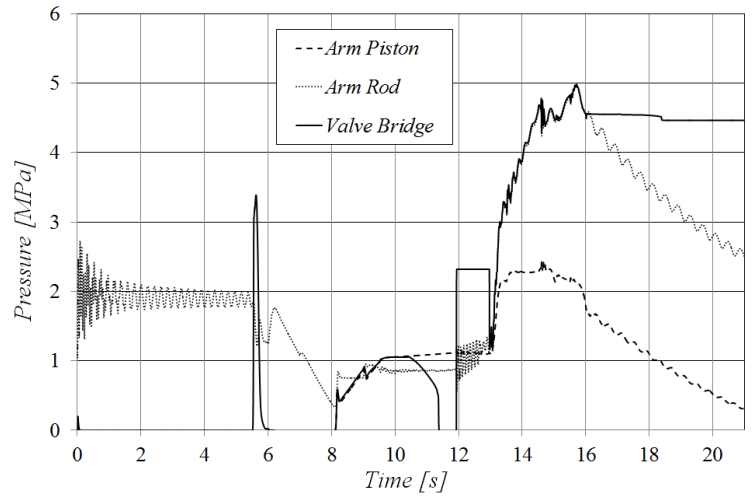

Fig. 27. Arm section pressures

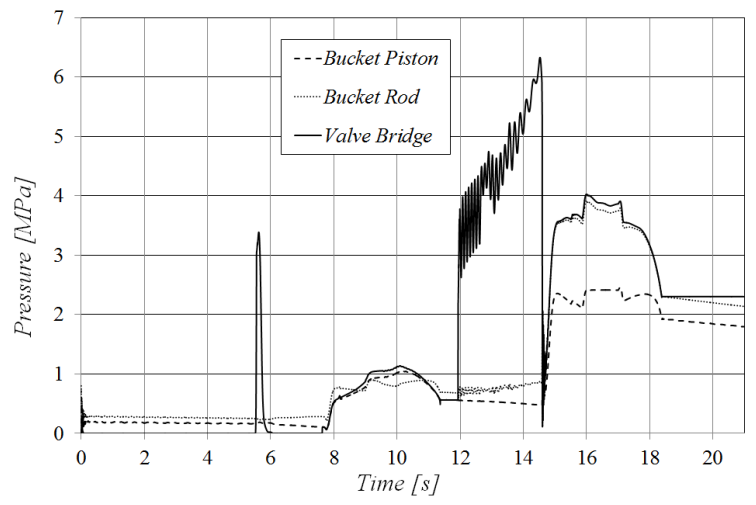

Fig. 28. Bucket section pressures

enables studying the system dynamic interaction in simulated actual load-sensing conditions where more than one section (multi-actuator) is used at the same time. The hydraulic model described consists of a grey box variable displacement pump model and a white box load-sensing, flow-sharing valve block model. The mathematical models have been validated and calibrated with stationary and dynamic tests in different conditions. The pump and valve models offer a satisfactory reproduction of realistic functioning conditions. The last section of the paper provides an

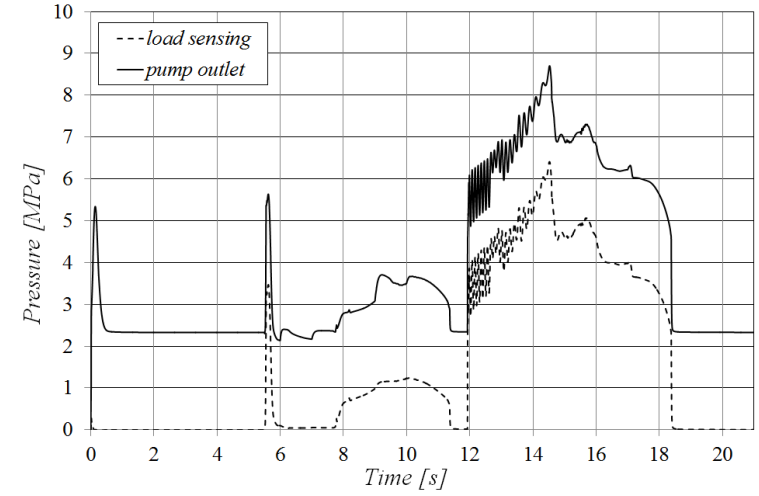

Fig. 29. Load-sensing and pump outlet pressure

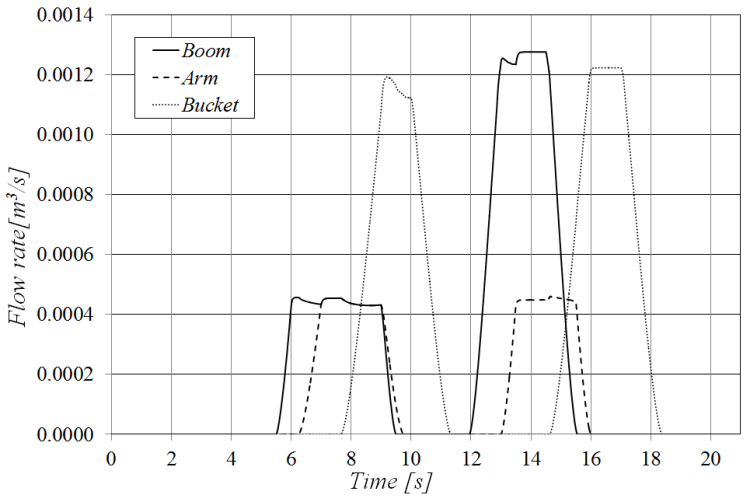

Fig. 30. Flow rates

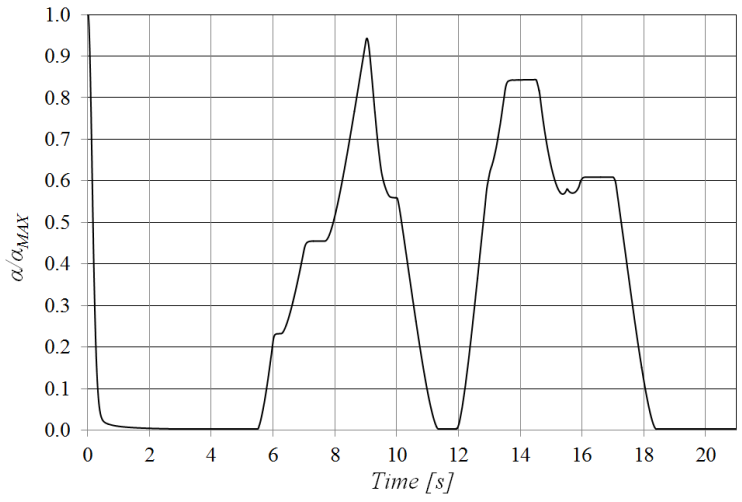

Fig. 31. Pump swash angle displacement

overall view of the hydraulic models capability coupled with the kinematics of an excavator. A combination of the various motions has been discussed, in an attempt to reproduce a realistic working cycle. The results presented show the potential of this model in aiding pump and valve designers in analysing/assessing the behaviour of their components when mounted in the entire system. The simplified modelling approach proposed enables replicating the most significant dynamics of the system components, during actual working conditions. Furthermore, the model proposed 
requires short computational times and may be used for "control-oriented" applications; once compiled in a dynamic linked library (DLL), the mathematical model is able to run real-time simulations on a suitable HiL platform for designing and testing control, and developing diagnostic strategies.

\section{ACKNOWLEDGMENTS}

The authors would like to acknowledge the active support given to this research by Casappa S.p.A. and Walvoil S.p.A. (Italy).

\section{NOMENCLATURE}

$A_{A C T} \quad$ Actuator piston area $\left[\mathrm{m}^{2}\right]$

c Viscous friction coefficient $[\mathrm{Nm} /(\mathrm{rad} / \mathrm{s})]$

$d_{A C T} \quad$ Actuator piston arm [m]

$J_{E Q} \quad$ Swash plate inertia $\left[\mathrm{kg} \cdot \mathrm{m}^{2}\right]$

$\dot{m} \quad$ Mass flow rate $[\mathrm{kg} / \mathrm{s}]$

$n \quad$ Shaft rotary speed $[\mathrm{r} / \mathrm{s}]$

$p \quad$ Pressure $[\mathrm{Pa}]$

$T_{A C T} \quad$ Actuator torque $[\mathrm{Nm}]$

$T_{n} \quad$ Barrel torque [Nm]

$V(x) \quad$ Control volume $\left[\mathrm{m}^{3}\right]$

$V_{d} \quad$ Pump displacement $\left[\mathrm{m}^{3} / \mathrm{r}\right]$

Theoretical flow rate $\left[\mathrm{m}^{3} / \mathrm{s}\right]$

$x \quad$ Spool position $[\mathrm{m}]$

Greek Symbols

$\alpha \quad$ Swash plate angular position [rad]

$\beta \quad$ Bulk modulus [Pa]

$\eta_{g} \quad$ Overall efficiency [-]

$\eta_{h m} \quad$ Hydraulic-mechanical efficiency [-]

$\eta_{v} \quad$ Volumetric efficiency [-]

$\rho \quad$ Fluid density $\left[\mathrm{kg} / \mathrm{m}^{3}\right]$

Subscript

$D \quad$ Delivery

$i \quad$ Volume index

$n \quad$ Piston index

\section{REFERENCES}

[1] Inderelst, M., Losse, S., Sgro, S., Murrenhoff, H. (2011). Energy efficient system layout for work hydraulics of excavators. $12^{\text {th }}$ Scandinavian International Conference on Fluid Power, Tampere, vol. 1, p. 177-191.

[2] Zimmerman, J., Ivantysynova, M. (2011). Hybrid displacement controlled multi-actuators hydraulic systems. 12th Scandinavian International Conference on Fluid Power, Tampere.

[3] Casoli, P., Gambarotta, A., Pompini, N., Riccò, L. (2014). Development and application of co-simulation and controloriented modeling in the improvement of performance and energy saving of mobile machinery. Energy Procedia, vol. 45, p. 849-858, D0l:10.1016/j.egypro.2014.01.090.

[4] Wu, D., Burton, R., Schoenau, G., Bitner, D. (2007). Analysis of a pressure -compensated flow control valve. In ASME Journal of Dynamic Systems, Measurement and Control, vol. 129, no. 2, p. 203-211, Dol:10.1115/1.1870037.

[5] Borghi, M., Specchia, E., Zardin, B. (2009). Numerical analysis of the dynamic behaviour of axial piston pumps and motors slipper bearings. SAE International Journal of Passenger Cars - Mechanical System, vol. 2, no. 1, p. 1285-1302, DOI:10.4271/2009-01-1820.

[6] Zecchi, M., Ivantysynova, M. (2012). Cylinder block / valve plate interface - a novel approach to predict thermal surface. $8^{\text {th }}$ International Fluid Power Conference, Dresden.

[7] Williamson, C., Lee, S., Ivantysynova, M. (2005). Active vibration damping for an off-road vehicle with displacement controlled actuators. International Journal of Fluid Power, vol. 10, no. 3. p. 5-16, DOl:10.1080/14399776.2009.10780984.

[8] Casoli, P., Anthony, A. (2013). Gray box modeling of an excavator's variable displacement hydraulic pump for fast simulation of excavation cycles. Control Engineering Practice, vol. 21, no. 4, p. 483-494, Dol:10.1016/j. conengprac.2012.11.011.

[9] McCloy, D., Martin, H.M. (1973). The Control of Fluid Power. Hellis Horwood Limited, London.

[10] Casoli, P., Vacca, A., Franzoni, G., Berta, G.L. (2006). Modeling of fluid properties in hydraulic positive displacement machines. Simulation Modeling Practice and Theory, vol. 14, no. 8, , p. 1059-1072, D0I:10.1016/j.simpat.2006.09.006.

[11] IS04409-1986. Hydraulic Fluid Power - Positive displacement pumps, motors and integral transmissions - Determination of steady-state performance. International Organization for Standardization, Geneva.

[12] Casoli, P., Anthony, A., Riccò, L. (2012). Modeling of an Excavator system - load sensing flow sharing valve model. SAE Commercial Vehicle Engineering Congress, Rosemont, DOI:10.4271/2012-01-2042.

[13] LMS Imagine - AMESim ${ }^{\circledR}$ (2011). Reference manual, The American Society of Mechanical Engineers, New York.

[14] Lin, S.-T., Huang, J.-N. (2002). Stabilization of Baumgarte's method using the Runge-Kutta approach. ASME Journal of Mechanical Design, vol. 124, no. 4, p. 633-641, Dol:10.1115/1.1519277.

[15] Marquis-Favre, W., Bideaux, E., Scavarda, S. (2005). A planar mechanical library in the AMESim simulation software. Part I: Formulation of dynamics equations. Simulation Modelling Practice and Theory, vol. 14, no. 1, p.25-46, D0l:10.1016/j. simpat.2005.02.006.

[16] Grzesikiewicz, W. (1998). Dynamics of a ground digging tool. XI. Scientific Conference Problems of Work Machines, Zakopane.

[17] Šulc, B., Jan, J.A. (2002). Nonlinear modelling and control of hydraulic actuators. Acta Polytechnica, vol. 42, no. 3, p. 41-47.

[18] Casoli, P., Gambarotta, A. Pompini, N., Riccò, L. (2015). Coupling excavator hydraulic system and internal combustion engine models for the real-time simulation. Control Engineering Practice, vol. 41, p. 26-37, Dol:10.1016/j. conengprac.2015.04.003. 